\title{
G.A. MARTÍN MARTÍN, Competencia, enriquecimiento y daños, Valencia, Tirant lo Blanch, 2019, 392 p. ISBN: 978-84-1313-818-3.
}

\author{
CARmen Herrero SuÁrez \\ Profesora Titular de Derecho Mercantil \\ Universidad de Valladolid
}

DOI: https://doi.org/10.20318/cdt.2020.5234

\section{Audaces fortuna juvat}

En los últimos quince años, uno de los principales focos de atención del Derecho de la competencia en Europa lo constituye, sin duda, la conocida como aplicación privada o private enforcement de las normas de competencia, que supone la valoración de las prohibiciones de prácticas restrictivas por parte de los tribunales del orden jurisdiccional civil. Pese a la variedad de los posibles efectos civiles de las prácticas anticompetitivas, el interés de doctrina y autoridades administrativas se ha centrado, mayoritariamente, en el ejercicio de acciones resarcitorias por los daños causados por dichas conductas en los patrimonios individuales, relegando a un segundo plano otras reacciones que, en el marco de las relaciones entre particulares, pueden derivarse de la infracción de las normas antitrust, tales como la solicitud de medidas cautelares y, muy especialmente, el ejercicio de acciones de nulidad y restitutorias. En este sentido, las distintas iniciativas, al menos desde una perspectiva de política legislativa, tal y como ponen de manifiesto las medidas europeas más recientes como la aprobación de la Directiva 2014/104/UE o la Comunicación sobre cuantificación del perjuicio, se centran en el daño derivado de infracciones de la competencia y el derecho a su resarcimiento. Esta política se ha ido articulando -y consolidando- sobre la base de determinados principios, especialmente el que veta o sanciona el enriquecimiento injusto, que ha sido esgrimido, bien para desterrar del sistema de daños por ilícitos competitivos determinadas instituciones, como los daños punitivos, bien, por el contrario, para dar plena carta de naturaleza a otras, como la excepción de repercusión de costes o passing-on defense.

Los retos que planteaba la necesaria transposición de la Directiva en el ordenamiento jurídico español, junto al incremento de acciones de daños, y el consiguiente surgimiento de nuevas dificultadas evidenciadas en la práctica, han suscitado el interés doctrinal, espoleando una intensa actividad productiva, manifestada en la publicación de un gran número de trabajos, generales o específicos. Una característica que comparten la mayoría de ellos es que el esfuerzo analítico se proyecta a partir de unos cimientos que, salvo excepciones, se admiten sin cuestionamiento. Una de estas bases inamovibles la constituye el principio de enriquecimiento injusto en el sentido anteriormente mencionado, es decir imbricado en la finalidad compensatoria de las acciones de daños y enarbolado como argumento reiteradamente repetido para negar la posibilidad de daños punitivos y como fundamento de la passing on defence... Entono el mea culpa. En las ocasiones en las que he tenido que ocuparme de esta materia, he admitido sin mayores recelos ni dudas el alcance y contenido de este principio.

En este contexto aparece la monografía de Gustavo Martín, Competencia, Enriquecimiento y Daños. El autor explica acertadamente la ausencia de intentos, doctrinales o jurisprudenciales, de una revisión crítica de este principio, afirmando que "nadie puede resistirse a la autoridad argumentiva de un principio como aquel que veda los enriquecimientos injustos" para desmentir $-\mathrm{o}$, al menos, matizar-, posteriormente esta afirmación. Puede cuestionarse la autoridad argumentativa de este principio. De hecho, este trabajo supone un radical cambio de actitud en la doctrina, construyéndose el análisis precisamente desde un cuestionamiento o revisión integral del papel que ha desempeñado $\mathrm{y}$, sobre todo, debe desempeñar el principio de enriquecimiento injusto en el marco del Derecho de la competencia.

Con carácter general, pueden destacarse diversas características de la obra comentada que la diferencian de otros estudios en materia de apli- 
cación privada y le otorgan, a mi juicio, un valor añadido.

En primer lugar, los planteamientos, reflexiones y, sobre todo, conclusiones del autor son el resultado de un trabajo sólido y serio de investigación. Esta monografía tiene su origen en una tesis doctoral, cuya defensa tuve la ocasión y el honor de valorar, formando parte del Tribunal que la juzgó. Tesis que, además, al margen de la máxima calificación académica que mereció en ese momento, ha sido objeto de reconocimientos posteriores, como el Premio Extraordinario de Doctorado de la Universidad de Salamanca o el "Premio José Manuel Gómez Pérez" a la mejor tesis de Derecho Privado, que acreditan su valía y contribución a la investigación jurídica. En ella encontramos análisis histórico, casuismo jurisprudencial y consideración ponderada e integradora de las soluciones adoptadas en otros ordenamientos jurídicos. Su autor, además, aúna la doble condición de investigador y juez. Su pertenencia a la carrera judicial acredita y refuerza el conocimiento de las instituciones que se manejan, al haberse acercado a las mismas no ya simplemente desde la pura reflexión teórica, sino desde la dificultad que entraña su interpretación y aplicación en la práctica.

En suma, las conclusiones del autor, se compartan o no, no son fruto de la inspiración repentina, ni de la ligereza de mente o de pluma, sino de un profundo conocimiento de las instituciones y principios jurídicos, de un espíritu crítico poco conformista y de un análisis exhaustivo, sólido y concienzudo.

En segundo lugar, la obra es enormemente valiente. Audaz en sus planteamientos, pero carente de temeridad. Si bien se cuestionan las propias bases dogmáticas sobre las que se apoya actualmente la aplicación privada del Derecho de la competencia, todas las críticas y planteamientos están sólidamente fundamentados. El autor es valiente porque se atreve a hablar claro. Habla del verdadero origen del principio de enriquecimiento injusto $\mathrm{y}$ su traslación acrítica desde el ámbito tributario, en el que ya se utilizó de manera cuestionable, al marco de las acciones de daños derivadas de ilícitos antitrust. También pone de manifiesto una cierta hipocresía por parte de la Comisión, denunciando el claro favoritismo del que goza el sistema de aplicación pública, evidenciado en una protección a ultranza de los programas de clemencia, enmascarada en ocasiones en un pretendido fomento entusiasta de la aplicación privada.
Por lo que a la estructura de la obra se refiere, el autor no tenía una tarea sencilla, ya que se enfrentaba al reto de cómo explicar la verdadera naturaleza y alcance de un principio que, aparentemente, parecía no requerir de ningún tipo de explicación para, una vez revisado, delimitar el papel, si alguno, que debería jugar en el marco de la aplicación privada del Derecho de la competencia. Fundamentalmente, era preciso examinar la solidez de uno de los dogmas que se consolida tras los casos Courage y Manfredi: la operatividad del principio de enriquecimiento injusto como límite del derecho de daños. Derecho de daños configurado además desde una perspectiva estrictamente compensatoria. Los tres primeros capítulos reflejan ese titánico empeño, analizando conjuntamente dos vectores fundamentales: el origen del principio de enriquecimiento sin causa y su traslación al marco de la aplicación privada y, paralelamente, las funciones del Derecho de daños, con especial hincapié en las excepciones a la función compensatoria, única admitida en el Derecho de la competencia. En el capítulo cuarto, se examina una institución a medio camino entre el Derecho de daños y el Derecho de enriquecimiento: la privación de los beneficios del infractor, el comiso de las ganancias obtenidas ilícitamente. Este capítulo prepara la entrada a la que, en mi opinión, constituye la principal aportación de la obra: un último apartado en el que se redefine la verdadera efectividad del principio de enriquecimiento injusto en la aplicación privada del Derecho de la competencia. Alejándose del cielo de los conceptos jurídicos, el autor ofrece dos propuestas de enorme e incuestionable importancia práctica: la utilización de la institución de la privación de beneficios en el Derecho de la competencia y una relectura de la defensa de repercusión de costes que permita solventar las dificultades derivadas de la regulación contenida en la Directiva y trasladada a los Estados miembros.

En conclusión, esta obra constituye, a mi juicio, una excelente ocasión para los juristas en su más amplio espectro, de adentrarse en terrenos hasta ahora poco explorados y muy sugestivos. Dotada de un estilo impecable que trasluce la erudición de su autor con numerosas referencias clásicas, es una obra de gran calidad científica cuya lectura y estudio constituyen, sin duda, un valioso ejercicio intelectual. Este trabajo no sólo viene a sumarse al acerbo doctrinal, ya numeroso, en materia de aplicación privada de las normas de defensa de la competencia, sino a enriquecerlo notablemente. 